\title{
Analyzing Core Drivers of Societal Changes in Ready to WeAR GARMENT INDUSTRY OF INDIA
}

\section{Abstract:}

Markets is a social system supplying society's material needs. In today's scenario in India, because of fast socio-cultural changes, audiences have high exposures, information and knowledge about trends, availabilities, options and uniqueness of products available and entering the market. Hence businesses need a very careful and cautious handling of the aforesaid fact in strategic planning. Manifestation of dominating societal aspects viz. social media, societal \& cultural changes, rise of newer market segments, vulnerable yet aspirational youth and growing consciousness in producers \& marketers are propelling the wheel of change in marketing strategies, in Indian garment market in the light of aspects like change in mindset \& attitude, changing life styles, quick changing buying \& usage behaviors, changing social exposures etc. In this context, companies require to analyze

\section{Keywords:}

societal changes; strategic planning; core drivers change drivers of the sector to consider changing societal elements and their impact on the target segments in order to frame sustainable marketing strategies. The significance of such "change drivers" has increased in recent years in India, especially after entry and success of "affordable Chinese product" in all the segments, making it essential to understand issues like changing mindsets and societal status of customers. Now such changes require in-depth study, analysis and inclusion in strategic planning to cater and engage the target better. This need of incorporation of changes drivers in strategic planning is studied in context to ready to wear garments sector of India as this sector it is not only about selling the product but it is all about selling a life style under changing customer perception. This study will help in understanding and incorporating changing societal influences to include them in strategic planning, product development and marketing with holistic approach.

\section{Author s data:}

1Faculty of Business, Royal Thimphu College Bhutan, sharon1822@gmail.com

${ }^{2}$ Facultv of Business. Roval Thimohu Colleqe Bhutan. Vibhutio189@umail.com

International Journal - VALLIS AUREA • Volume 5 • Number 2 • Croatia, December 2019

UDK 658.8.012.2(540); 001 10.2507/JJVA.5.2.2.63 


\section{Introduction}

Beyond doubt, marketing is an economic process that is affected by societal influences at every level, directly or indirectly, from basic to most competitive strategic aspects. Marketing needs to be treated more as social institution rather than truly commercial which needs to be handled carefully in the markets which itself is a social system supplying society's material needs. This new era of holistic marketing demand transformation of marketing philosophies in line to societal changes like changing social status, changing requirements, changing cultural values changing social recognitions , changing perceptions, changing mindsets etc. towards better value creation or rather, creating better customer perceived value in production, marketing and in customer services too.

In today's changing market scenario in India, because of fast socio-cultural changes, audience have high exposures and information on every aspect ranging from quality to alternative products. Markets need a very careful and cautious handling of strategic planning. While developing a marketing strategy brands cannot survive only on traditional marketing models but require to add changing element that have started influencing the target segment more than the established ones. To frame sustainable marketing strategies such elements require in depth studies, understanding and appropriate inclusion in planning. Change in mindset, attitude, life styles, buying \& usage behaviors, social exposures are now more prominent to be taken cared over traditional strategic approaches. The significance of such societal aspects has increased in recent years in vast \& vital Indian market after entry of
Chinese products which have made it possible that "everything is available and affordable for every segment". Now class differences have vanished in product usage making customers to become more demanding, informed and cautious about "social self". Such mindset change and societal changes have changed the whole market scenario and made the producers \& marketers to rethink, redesign and reengineer the strategies to sustain in highly competitive markets. It requires in-depth study, analysis and inclusion of such changes in strategic planning to cater and engage the target better.

This growing need of incorporation of societal changes in strategic planning is studied in context to ready to wear garments in India ,as this sector is most influenced by societal changes, ever changing and highly demanding where it is not only about producing and selling the product but it is all about creating \& selling a package of life style to establish relationship with the most vulnerable customer .

\section{GROWING SIGNIFICANCE OF SOCIETAL ASPECTS IN MARIKETING PLANNING}

Over the past several years Indian industries have shown tremendous growth in every sector building up on capacities at various levels, expanding its product base, incorporating innovative technologies and coming out with new avenues of businesses using latest tools like social media, ecommerce etc. Garment sector in India has also changed tremendously after the boom of Chinese garment industry which is practically making every country a target market. Costing, production, designs, labels, raw materials, accessories, every 
aspect of garment business is either facing tough Chinese challenge or changing due to that pressure. Under pressure, Indian garment sector is now coming up as more organized sector than ever and searching new avenues through strategic reengineering. Such avenues require inclusion of societal changes in lifestyles, norms, values ,culture, adoptability , demographic changes and consumption patterns etc. to make it sustainable. Some of the key growth drivers of the ready to wear garment industry in India are observed as disposable income, rise in nuclear family, larger young population, changes in consumer wants, quality products, affordable product attributes and improved buying intensions, desire for individual recognition, enhanced awareness etc. Under such growing market scenario, there has been a rapid increase in market-size of ready-towear clothing apparel brands in India dominated not only by local brands but by global brands too. Complex desires for cheap but branded products in exclusive \& casual ranges has made marketers to realize that the product must be produced more audience focused rather than product focused to match changing customer perceived value and economic viability. Now the slogan "Survival of the fittest" has actually became "survival of the smartest" in the sector. This approach will be more efficient and delivering the right mix to the right group of people. The time now demands to incorporate such social changes in strategic decisions to broaden the aspect of customer socialization further in this era of social reforms and social media dominance. Now it is a time to include societal aspects in value dimensions and nolistic marketing.
Garments is a serious business because product development here is the most venerable aspect than any other business as every collection, every season has to be unique in design and technique to give audience every time a new look which is a real tough task beyond any doubt. It's not like other products where, as per the market research you develop your product once in a year or two and market it in your targeted segment. It requires strategic planning and "smart understanding" of the continuous changes occurring in segment and to be always on toes as the sector operates in 3 to 4 seasons every year and well dominated by elements like new look, new product, best price, best quality, fast production technique, perfect timing and quickest placement of the product. This can't be achieved without through understanding of changing scenario and incorporating them smartly in strategies. Irony of product development here is, manufacturer's value creation is not taken by the customers and individual customer's value perception (CPV) plays vital role in most challenging way than any other product marketing.

In this new age ,where social marketing has been taken as part of smart communication process the "societal marketing" is shaping up as part of better understanding the segment regarding product requirement, usage, preferences etc. which helps further in product designing, product development, branding, positioning and finally to its acceptance. This is an focused approach to deliver more value- product to the unique audiences of ready to wear garments. For a good marketing performance on economic fronts it becomes vital in current markets of competing global players. Now, a garment retailer must 
determine how to successfully acquire, engage, attract, sell to, and retain the diverse \& demanding customer who is always looking for something new \& exciting under the influence of fast track market communication, product availability and choices. Global brands have made this even more easy as well as complex both. Now it is necessary to gauge the mindset of this style conscious, ever changing consumer correctly. Consideration of societal aspects will help in doing so and bringing forth the right product offerings to the right consumer at right time. With vast availability of options, changing trends , copy pasting of designs, higher buying powers and zero waiting time, the market is totally different than what it was 10 years back. Technology and socio-cultural shifts have enable new shopping behaviors, allowing consumers to deal directly with other fellow consumers, compare prices , customize products, gather latest information and get the best deal. In this dynamic environment, gaining in-depth insight into consumers' lives, attitudes and motivations is now a competitive advantage through "smart understanding" of the customer.

\section{LITERATURE REVIEW}

[51]in write up "Megatrend Analysis-Putting the Consumer at the heart of business - A Euromonitor International Report" described that a megatrend is a shift in behavior or attitude under societal changes that has global impact and exists crosses multiple industries. Megatrend analysis allows companies to build a long-term strategy that is proactive rather than reactive, making sense of where they stand today, but also ensuring they have a plan to remain relevant moving forward under changing market expectations for value. Therefore manufacturers and marketers need to study, analyze and understand mega trend change and aspect of Customer Perceived Value for their target audience in developing the product. This is not an easy task as this is influenced by changing market scenario where factors like societal changes, quick changing trends \& demands, changing technologies and Globalization has a great impact. According to Investopedia "The consumer's perceived value of a good or service affects the price that he or she is willing to pay for it." - Perceived value is "the worth that a product or service has in the mind of the consumer."

Ready to wear garment market is very unique from a customer value perspective. As it was said by author [49], companies should emphasize more on providing unique added value rather than modifying core benefits in order to enhance customer value and loyalty.

Almost three decades ago it was noted by author that a competitive advantage of a firm comes from its capability to create value for its customers that exceeds the company's costs of creating it. This perception has not changed up to now as superior customer value delivery is still seen as a key to achieve and maintain competitive advantage. This had led to an increased interest of researchers to analyze customer value creation process and how customers perceive value.

Some authors suggested that customer's perceived value consist of 5 components: price, product quality, service quality, image and relationship between a customer and a vendor.

Ready to wear garment market is very unique from a customer value perspective. The core benefits or basic requirements for supplier are more or less 
similar in all B2B \& B2C industries. But the add-on benefits are very specific for each industry. As it was said by author [49], companies should emphasize more on providing unique added value rather than modifying core benefits in order to enhance customer value and loyalty. It is essential for suppliers in this industry sector to know what their customers expect, how they perceive value and what add- on benefits could be offered to them. It will be reviewed that what are the components that authors perceive as adding value for "value perception by customers" and what are the elements considered to be valuable for the customers in ready to wear garment markets.

The customer value creation has long been considered as a central marketing concept and the source of competitive advantage [35]. Nevertheless, customer value and its creation differ substantially in each industry. Therefore, literature suggest firstly starting with the value exploration process to gain understanding what customer thinks about, wants, does, and worries about. Only then they propose to proceed with value creation process utilizing all the resources and competencies available.

The company's resources or assets used to create customer value are usually divided by authors to tangible [physicall and intangible (intellectual] dimensions [7]. [34] They have introduced the operand and operant concepts to describe company's resources. They define operand resources as tangible and static goods offered to customer that the goods-centered model of exchange is based on. Whereas service-centered model of exchange is based on operant resources that are invisible and intangible assets such as core competences or organizational processes.
Usually authors use the term core product to describe the value created for the customer by delivering the physical or tangible goods. Core product can be viewed as the product in its most basic form. The concept of core product has been defined by some authors who suggested four Ievels of product offer: core or generic product, expected product, augmented product and potential product. The only difference is that authors emphasizes the difference between the core benefit, which is explained as the advantage the buyer actually wants and the generic product, which represents the actual physical product. Despite the industry differences, some authors distinguish the most basic and general dimensions of a core or physical product in general.[6] operant resources are not material or physical assets but invisible and intangible processes of a company [34]. According to [16] operant resources are resources that produce effects such as customer value creation. According to the dominant service-centered view, based on operant resources, companies should identify and develop their core competences, expertise, substantial skills and knowledge and cultivate relationships with customers that involve them in developing the value propositions according to the specific needs of the target segments. [34] The service value has been, and will continue to be, a key construct of interest to marketers. The importance of service value emerges from consumer decision processes that are usually based on service value [18]. According to [12], service is any act, performance, or information that enhances the firm's core product. Authors define customer service as the value adding attempts, activities and practices 
that complement the core product provided by a company.

According to [15], core competence is a connection of skills, expertise and knowledge of the employees that enables the company to perform their tasks and accomplish results at a high standard. As mentioned above, the third component of service value in this paper is complementary service. The concept of complementary service has been characterized using various terms, including complementary selling, companion selling, complementarities, and complementary product or augmented product offering. In case of ready to wear garment market, the complementary to each feature service is offering the extended range of products that customers need in a production, presentation and selling processes. The range might vary from the materials and type of the customer to product presentation..

According to [34], companies should develop and cultivate relationships with customers by involving them in developing personalized, competitively compelling value propositions to meet their particular needs. One of the tools that are most often used to create relationship value for customers particularly in business-to-business marketing is customer relationship management [14]. Customer loyalty can be defined as a customer's engagement with a company and willingness to continue doing business with a company permanently[39]. According to some authors, loyalty is "a deeply held commitment to rebuy a preferred product or service in the future despite situational differences and marketing efforts having the potential to cause switching behavior". Behavioral loyalty is interpreted as the type of customer behavior such as repeat or continuous purchasing from the same supplier or the act of recommendation [36]. Behavioral dimension was the first and mostly used dimension of lovalty by researchers. Even with current definition of loyalty includes more than just a behavioral dimension; some researchers still focus only on behavioral dimension of loyalty [22]. Attitudinal loyalty is described by author [20] as different opinions that create a general attachment to a product, service, or organization [22]. The criticism of behavioral loyalty by author [19], arguing that loyalty develops as a result of a conscious effort to evaluate competing brands, has led to the increased attention to attitudinal loyalty by authors and became an important loyalty dimension[22]. Attitudinal loyalty can be created and maintained by focusing on relationship building and creating customer's trust, commitment and again providing excellent service systems.

The study by author [8] has researched the relationship between the perceived core product value and customer satisfaction and loyalty. The most important dimensions of core productquality and price - were measured. Authors have found that perceived product quality and perceived price fairness are both positively related to customer satisfaction which they explain by product quality and price being the essential concerns to customers and therefore effecting their satisfaction [8]. Despite the vast literature on customer service and satisfaction relationship, very few authors have explored the relationship between customer service and loyalty. Usually, the ones who did researched the indirect relationship via satisfaction because satisfaction is thought to be an immediate antecedent to loyalty Competence 
can be described as intangible assets of the organization such as skills, knowledge or expertise, which are used to create value for customers. The increased authors attention and emphasis on competence as a way to create customer value has resulted in numerous studies researching the company's competence relationship with customer satisfaction and Ioyalty. Authors explain the relationship between company's competence and customer satisfaction based on the notion that meeting or exceeding customers' expectations achieves satisfaction. Nevertheless, there is still scarce of research on the relationship between competence and customer loyalty.

[5], while describing the marketing actions for the garment industry mentioned that designer label, a private label or even a little brand name, they are different on the level of the product exclusivity, perceived quality and reliability; but they are all talking about image marketing, and would like to use brand as a tool to seize larger market share in their market. [29] on their article on Branding of Clothing Fashion products argue that clothing with high branded images has a great impact in garment market to satisfy the desire of customers. Due to the increased awareness and consciousness, people are ready to spend any price for comfort and quality related to strong branded apparel.

\section{CORE DRIVERS LEADING SOCIETAL CHANGES}

In order to understand the core drivers of societal change in the sector which in turn influence the product development, branding and marketing , a focus group was established to get expert opinion, suggestions and feedback on core drivers of change in the sector. The focus group represented every kind of representative of the sector as under; 1. Fashion designer from Noida; Shweta Mehra from Rabbana fashion Pvt.Itd.

2. Retailer from Karol Bagh; Anil Batra from Frontier Raas

3. Merchandiser from Noida; Ankur Batra from Ecru fashions

4. Wholesaler from Chandni Chowk; Anil Soni from Bhairav embroideries Pvt.ltd

5. 05 Customers from South Extension, Okhla, Karol Bagh , Connaught place and Chandni Chowk

6. Production manager from Okhla industrial area -garment factory Sanjay Sharma

Personal interaction with open ended questions lead the findings on the change drivers to some specific factors which were considered and emerged as most dominating factors of the sector. Following factors have emerged as the core drivers of societal change that influence the buying behavior of target segments and in turn enforce need of incorporating such societal changes into strategic formulation.

\section{Demographic and Psychographic Change}

Changing status of women in society and positive mind set change towards the same have changed the way of life in Indian markets too. In each segment we could observe distinct taste and likings which does not depend on the disposable income of a person rather than mind set and the life style of the consumer at large. 
Demographic shifts such as urbanization, migration, higher life expectancy, falling birth rates and the increasing population of elderly people, are combining to reshape consumer lifestyles and purchasing decisions today.

\section{Technology Impact}

Today, customer has become more informed and recognition prone and each segment is getting affected by technological changes too in different ways. Though the intensity depends on their level of thought, profession, education, and exposure to the world but its influence is beyond any questions. The constant innovation within technology and ever-updating technological processes are driving consumer trends in current garment markets.

\section{Changing Values}

The changing values, priorities, perceptions, attitudes, beliefs and motivations shape decisionmaking, from policy to purchases. Generational shifts, cultural changes, as well as changing socio-political scenarios such as concepts like Smart Cities and Smart Homes, Healthy living, ethical Living, Reinventing Gender Roles, Changing Family Dynamics, Multiculturalism etc. are changing the behaviors in buying as well as in perceptual process.

\section{Middle Class Extension}

Marketers and producers of the sector feel boom, extension and even retreat about the middle classes in India. At the same time, the middle classes, in developed markets, struggle to maintain their economic position , exemplifying the unique features like the growth of discounters and on other hand trying to jump out of the strata. This contrasting trend heads on placing more emphasis on the consumer experience as social being and as a vehicle for boosting sales on other face has lead the garment businesses to new dimensions.

\section{Shifting Market Frontiers}

As the areas of the markets become over- explored, over-populated, or otherwise have reached their maximum potential, marketers gain prominence for their unexploited potential. We call this "Shifting Market Frontiers" and there is need to adapt to the changing demographic, economic and technological reality, bringing new markets from frontier into the spotlight.

\section{Generated needs}

Motivation behind consumers' purchasing decisions has changed in today's scenario vis a vis factors like their quick societal \& economic status change. At its core, the idea behind is "with more brands available even at more price points than ever before, consumers can spend more on the things that matter to them to maintain that acquired status, ego, image etc.". Brands are playing with " generated fake/genuine needs" for such changing customers . Changing "self concepts" have started dominating the market demands in garment industry.

\section{Reinvented Shopping}

How we buy goods is constantly in flux as economic and technological realities change every day for businesses and consumers. Shifting values and access to the internet have created a great deal of new competition for customers. Consumers make 
purchases across many platforms in sectors like garments and merchants must be prepared to engage anytime \& anywhere as new buying habit shift than any other sector. Nowthe ideal customer journey weaves a brand into the entire experience, providing value before, during, and after the purchase, converting a transaction into a relationship. Consumers are increasingly expecting retailers to engage with them in ways that suit their interests and lifestyle. Aspects like selling via social media and social messaging (scommerce), internet-enabled subscriptions, popup shops, native marketing and many more innovative methods that offer new ways to the growing markets of high competition. Garment market is among the leading ones in this category.

\section{Connected Consumers}

Connected consumers are the new trend of markets now, not only for references and opinion but also for feedbacks and supports. Over the years, international brands like Marks \& Spencer, Lacoste, Swarovski, H\&M, Mango, international designer brands like channel, Gucci, Karl Lagerfeld, Armani, tommy Hilfiger are among a host of others who have come into India through the franchise route using this connectivity aspect of consumers worldwide. These digital connections are underpinning shifts in how consumers live, work, and shop along the globe.

\section{Changing Culture, Subcultures and Cross cultures}

Culture refers to the shared beliefs, behaviors and attitudes that characterize a society. Culture prescribes the way in which one should live. One could find a difference in style, price preferences, color choice, fashion and even in size requirements some times. It is seen that economic environment and socio-cultural changes and its effect on buying habits of Indian consumers have led to a noticeable change in the lifestyle of people and consequently the buying behaviour of people, especially in the urban areas.

\section{Social Class Restructures}

The rise of the middle class in India is creating opportunities for many companies especially in garment sector. On one hand, they want their perceived value and on other they wish it to be cheaper too. Companies have managed to capture this change in the form of market share by introducing "lower echelon" brands without damaging their luxury brands. Pantaloon, W, Biba, Good Earth, Life-Style , Feb India are example of such consideration in strategy.

Changing Roles of Reference Groups, Opinion Leadership and Family structures

With changing roles in family structures, decision making, quality of information, reference group dynamics, opinion leadership the scenario is changing in garment sector too . Professionals of production and marketing need to get aware of this changing scenario by using different techniques to reach true opinion leaders to accommodate their references on strategies as in clothing industry it has a great deal of influence.

Perceived value , global awareness, service preferences and brand flooding

Ready to wear garment market is very unique from a customer value perspective . Changing Global exposures on styling, has emerged greatly under global influences. Customers have exposures of 
global brands now and also they get exposure on movies, net, you tube etc. for recent trends, changing trends and current successful products. Accordingly customers try to buy /use those for themselves

\section{CONCLUSION}

Core drivers of change are responsible to bring societal changes into importance in strategic formulation and making its marketing significance felt and recognized over traditional marketing ,production \& branding strategies. In garment industry , especially in ready wear sector societal aspects helps to understand the changes occurring and predict those occurring in the future .Is a now a critical tool for making strategy shift from reactive to proactive in context to present scenario. Societal aspect analysis helps businesses better anticipate market developments and lead both incremental and disruptive change for their industries \& markets. social marketing has been taken as part of communication process where as societal marketing should be the part of understanding the segment regarding changing product requirement, usage, preferences etc. which will help further in designing, product development, branding, positioning and its acceptance in markets towards demand and production accordingly.

The Indian customer has undergone a remarkable transformation in last 20 years in this sector. Organized retail with its variety of products and multitude of malls and supermarkets is fueling their addiction for newer expectations. But one thing is true beyond doubt that Most customers' preferences change according to the societal changes occurring around them which in turn bring change in fashion oriented requirements. Most consumers have grown up with television, the Internet, and have been exposed to the standards of living and consumer culture abroad. So, the technology, ideas and lifestyles are moving concurrently and quickly in this sector too like many core sectors especially after the global brand boom in last decade. People buy branded clothes because of their perceived quality and value. People wear branded clothes not only because of comfort but it is a matter of recognition and uniqueness for them now. People get influenced by design and style offers of the "branded" garment industry but from core of heart it is a matter of getting value for money, time and efforts against their formed expectations for it through environmental stimuli received from company communication, competitors, opinion leaders, references etc. Now the reasons why companies need to adopt the societal marketing concept lies within these elements of change coming from lifestyles, cultures status, trends, behaviors and societal changes. This study will help in understanding the need for incorporating changing societal influences in strategic planning towards development and marketing of right products.

\section{REFERENCES}

[1] Andrea Prothero [1990), Green consumerism and the societal marketing concept: Marketing strategies for the 1990's, Journal of Marketing Management, 6:2, 87-103,

[2] Apisit Chattananon (2003), the impact of societal marketing programs on customer attitudes toward corporate image in Thailand 
,Faculty of Business, University of Southern Queensland

[3] Anselmo Ferreira, Vasconcelos Cad [2011] ,Societal marketing concept and spirituality in the workplace theory: finding the common ground

[4] Abheek Singhi, Nimisha Jain [2017), The New Indian: The Many Facets of a Changing Consumer - BCG study in India

[5] Asseal H.( 1995], Consumer Behavior and Marketing Action, International Thomson publishing New York

[6] Alfansi, L., \& Sargeant, A. (2000). Market segmentation in the Indonesian banking sector: the relationship between demographics and desired customer benefits. International Journal of Bank Marketing , 18 [2], 64-74.

[7] Allee, V. [2009). Value-creating networks: organizational issues and challenges. Learning Organization , 16 (6), 427-442.

[8] Bei, L., \& Chiao, Y. [2001). An integrated model for the effects of perceived product, perceived service quality, and perceived price fairness on consumer satisfaction and lovalty. Journal of Consumer Satisfaction Dissatisfaction and Complaining Behavior , 14, 125-140.

[9] Bitner, M. J. (1995). Building service relationships: it's all about promises . Journal of the Academy of Marketing Science, 23(4), $246-251$.

[10] Brassington, F., \& Pettitt, S. [2006]. Principles of marketing. Financial Times Management, Harlow, London.

[11] Cuthbertson, R., \& Laine, A. (2004). The role of CRM within retail lovalty marketing. A Journal of Targeting, Measurement and Analysis for Marketing , 12 (3), 290-304.

[12] Capon, N. [2009). Managing marketing in the 21st century: developing and implementing the market strategy.

[13] Caruana, A. [2002). Service loyalty: The effects of service quality and the mediating role of customer satisfaction. European Journal of Marketing , 36 [7], 811 - 828.

[14] Christopher, M., Payne, A., Ballantyne, \&D. (2008). Relationship marketing: creating stakeholder value.

[15] Coyne, K., Hall, S., \& Clifford, P. (1997). Is your core competence a mirage? . 40-55.

[16] Constantin, J.A., Lusch, \& R.F. [1994]. Understanding resource management. Irwin Professional.

[17] Cravens, D., Grant, K., Ingram, I., Laforge, R., \& Young, C. (1992). In search of excellent sales organizations. European Journal of Marketing , 26 [1], 6-23.

[18] Cronin, Brady, Brand, Hightower, \& Shemwell. (1997). A cross- sectional test of the effect and conceptualization of service value. Journal of services marketing, 11 (6), 375-391.

[19] Day, G. (1969). A two-dimensional concept of brand loyalty. Journal of advertising research , 9 [3], 29-35.

[20] Fournier, S., \& Yao, J. (1997). Reviving brand loyalty: a reconceptualization within the framework of consumer-brand relationships. International Journal of Research in Marketing , 14 [5], 451-472.

[21] Florence Beno [2007], Societal communication and brand equity, International Conference on Brand Management, BirminghamUnited Kingdom.

[22] Gremler, D., \& Brown, S. (1996). Service loyalty: its nature, importance, and implications. Advancing Service Quality: A Global Perspective , $171-180$.

[23] Gi-Du kang, Jaffrey james [2007), Revisiting the concept of a societal orientation conceptualization and delineation, Journal of business ethics 
[24] Hae Joo Kim (2005), The Effects of CauseRelated Marketing on Company and Brand Attitudes , Seoul Journal of Business -Volume 11, Number 2 [25] Jeff Tanner, Mary Anne Raymond (2012], Marketing Principles - societal-factors , .lardbucket.org

[26] Jeanna Heeraman [2015], Whatinfluences-consumer-perception-of-value, mycustomer.com

[27] Jeanette Mulvey (2010), marketing should target opinion leaders not the masses, businessnewsdaily.com

[28] Maria Rumpf , Jena [1996 ], Making a Difference - The societal marketing concept supporting educational and cultural issues, Social Impacts Assessment- Shell.com

[29] Md. Mazedul Islam and Adnan Maroof Khan ( 2003), Branding of Clothing Fashion products: Fashion Brand Image Development by Marketing Communication ,Approach Research Journal of Engineering Sciences Vol. 2[4], 28-33,

[30] Marketing in the 21st century customer value: The next source for competitive advantag. [2017].

[31] Paul N. Bloom, Steve Hoeffler, Kevin Lane Keller and Carlos E. Basurto Meza (2006), How SocialCause Marketing Affects Consumer Perceptions,MIT Sloan management review

[32] Taposh Ghoshal (2015), Impact of Culture on Indian Consumers: An Exploratory study ,Springer link

[33] Veena Chattaraman(2010), The Indian Consumer,Department of Consumer Affairs, Auburn University

[34] Vargo, \& Lusch, \&. (2004). Evolving to a new dominant logic for marketing. Journal of marketing, 1-17.

[35] Woodruff, R. [1997). Customer Value: The Next Source for Competitive Advantage. Journal of the Academy of Marketing Science, $139-153$.
[36] Yi, Y. (1990). A critical review of consumer satisfaction. Review of marketing, 68-123.

[37] Yakup Durmaz Hasan (2012), The Influence of Cultural Factors on Consumer Buying Behaviour and an Application in Turkey. Kalyoncu University, Turkev -Global Journals,Volume14/4

[38] Zeithaml, V., Berry, L., \& Parasuraman, A. [1996]. The behavioral consequences of service quality. The Journal of Marketing , 31-46.

[39] Zineldin, M. (2006). The royalty of loyalty: CRM, quality and retention. . Journal of Consumer [40] Jean L. Druesedow (2004) ," Ready-toWear"

[41] Fashion Marketing book Third Edition [2010] ,Edited by Mike Easey , John Wiley \& Sons, Ltd., Publication

[42] Indian retail seen doubling by 2020: CIIBCG study, 2016

[43] Apparel Industry In India Last updated: November, 2016

[44] Indian retail industry analysis December 01, 2016

[45] Textile and apparel Nov-2016 IBEF Report

[46] Aditi Bajpai (2016),Reinventing traditional Indian fashion with a modern twist

[47] Satish Kota [2016),Importance of branding for Indian SMES

[48] T.S Devaraja (2016), Indian textile and garment industry an overview, Department of Commerce University of Mysore Hassan, India

[49] Hutt,\&Speh,\&. [2007]. Business marketing management: B2B.

[50] Small Business Trends [ 2004], "Marketing to Opinion Leaders,"

[51] Sarah Boumphrey, Zandi Brehmer [2014] ,Megatrend Analysis Putting the Consumer at the Heart of Business 